\title{
A conceptual framework for intelligence-based public health nutrition workforce development
}

\author{
Roger Hughes* \\ Nutrition Unit, School of Health Science, Griffith University, Gold Coast, Queensland 4217, Australia
}

Submitted 23 October 2002: Accepted 14 February 2003

\begin{abstract}
Objective: This paper describes a conceptual framework and associated intelligence requirements for problem-based workforce development for public health nutrition. Methods: A conceptual framework for public health nutrition workforce development was constructed based on a review of the literature and consideration of the intelligence needs to inform workforce development planning.

Results: A cyclical conceptual framework including five intelligence-linked components including public health nutrition problems and priorities, solutions and best buys, work needed, capacity to do the work and workforce development needs. This framework applied to the Australian situation illustrates its applications in workforce development research and planning. Although the existing availability of workforce development intelligence in each of these components varies, the framework does provide a systematic approach for workforce development research and planning directly related to public health nutrition problem resolution.

Conclusions: This framework highlights deficiencies in the existing public health nutrition workforce development intelligence and the need for further research to inform workforce development strategy planning
\end{abstract}

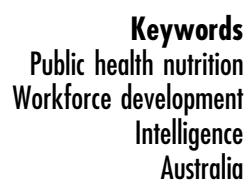

Building infrastructure to increase societal capacity to address nutrition issues is an important element of public health nutrition practice. Infrastructure in this sense includes policy development systems, intelligence gathering systems (such as monitoring and surveillance, intervention research and evaluation), workforce development and programme delivery systems that direct and support action to promote, protect and maintain population health ${ }^{1}$. In many countries, the capacity of society to organise responses to nutrition-related issues is determined largely by publicly funded health infrastructure such as health departments, universities and nongovernment organisations. A large component of this infrastructure is the health workforce. Increasing capacity via workforce development to deal with the diverse range of public health nutrition problems continues to be a major challenge in many countries ${ }^{2}$.

Public health workforce development scholarship in the $\mathrm{USA}^{3,4}$ has identified a range of barriers associated with workforce development that have relevance for public health nutrition, including:

- a lack of data enumerating and profiling the public health workforce and its continuing education needs;

- a lack of consensus about the basic and cross-cutting competencies or curricula needed in public health;

- a lack of an integrated system for life-long learning;
- inadequate incentives for participation in training and continuing education;

- absence of a uniform approach to individual, programme or system evaluation;

- financing of workforce training and continuing education is hampered by the absence of a coherent policy and funding strategy framework;

- no national framework for certification/obtaining credentials;

- limited research to evaluate the relationship among individual competency, organisational performance and health outcomes; and

- limited data regarding effective strategies for sustaining workforce preparedness and translating research findings into interventions ${ }^{3,4}$.

Many of these barriers are epistemological and point to the need for information from various sources that can guide effective and systematic strategy development and problem resolution (hereafter referred to as intelligence). Intelligence-based approaches attempt to reduce the effect of these limitations by building on evidence-based knowledge to include information collected from methods outside the discipline-specific and quantitative methods. For example, intelligence about workforce development may be enhanced by information from qualitative methods such as depth interviews, organisational review, 
reflective practice and community or stakeholder consultation.

Workforce development needs to be considered systematically rather than being simply a product of training. A major impediment to progress with workforce development is equating public health workforce development with training, rather than understanding it as a system for preparedness ${ }^{3}$. Investment in training without supporting structures to maintain and reinforce the effects of training is unlikely to be a high-yield strategy ${ }^{5}$. These are important points because much of the available literature that relates to public health nutrition workforce development has focused on training as the basis of workforce development ${ }^{2,6-9}$, with limited reference to the other capacity-building components such as organisational support, leadership, resource allocation and partnerships ${ }^{10}$. The literature on training for public health nutrition workforce development has been mostly discipline-based $^{6-8,11,12}$, although some authors have argued for multidisciplinary approaches ${ }^{13}$. Pelletier has argued that the disciplinary and interdisciplinary approaches to public health nutrition are insufficient for generating effective and sustainable solutions and that problem-oriented approaches are required ${ }^{14}$.

In the current paper, a framework for problem-based systematic workforce development considerations in public health nutrition is presented to extend a problembased approach to workforce development for public health nutrition and explore the related intelligence requirements.

\section{Workforce development conceptual framework}

The following conceptual framework for systematic workforce development has been developed by drawing on the peer-reviewed and non-peer reviewed workforce development literature ${ }^{3-5,15-19}$, with particular emphasis on identifying the intelligence needs of this system.

This framework, conceptualised in Fig. 1 and described in Table 1, is underpinned by the following principles:

1. Access to intelligence is central to the workforce development process and is a prerequisite for strategy effectiveness.

2. The system is cyclical in nature with inter-relationships between adjacent components of the system.

3. Effective workforce development will change the problems and priorities (i.e. produce favourable public health nutrition outcomes).

The cyclical nature of this model reflects the numerous possible starting points for strategic investigation of, and investment in, workforce development. It also illustrates the ongoing need for the application of different types of intelligence information for workforce development planning.

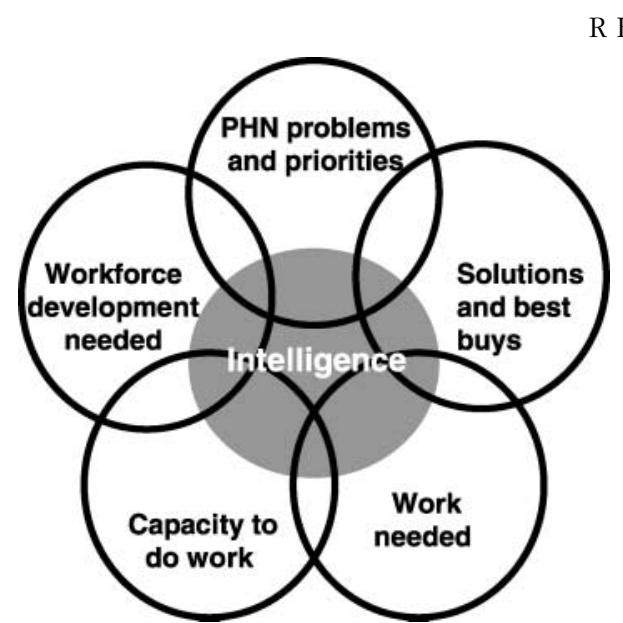

R Hughes

Fig. 1 Intelligence framework for problem-based workforce development in public health nutrition (PHN)

\section{Framework components}

\section{Problems and priorities: the need for organised action}

Diet and nutrition is widely acknowledged as a major factor affecting population health and well-being. Burden of disease studies ${ }^{35,36}$ and economic estimates of the cost of diet-related diseases ${ }^{37}$ have been used to illustrate the scale of the diet-related disease problem and inform policy and strategy development in Australia. The problems identified from this intelligence reflect those found globally, such as spiralling obesity rates, the high burden associated with cardiovascular disease, diet-related cancers and diabetes ${ }^{38,39}$. As in many countries, prioritising action in Australia is aided by national nutrition strategy development processes that have considered priority action areas based on methods such as broad community and professional consultation and evidence review ${ }^{20,40}$. These various sources can assist workforce development by identifying which problems the workforce needs to focus on.

\section{Solutions and 'best buys'}

Information about the effectiveness of public health nutrition interventions is an important aspect of the public health intelligence required to optimise public health nutrition action.

Intelligence from intervention research in Australia is limited, but there is much that can be gleaned from international research. Campaigns that have been relatively successful in dealing with public health problems in the past include those targeting smoking, not wearing seatbelts, drink-driving and poor immunisation rates. Analyses of these campaigns have helped to identify features that may provide important leads for public health nutrition interventions ${ }^{38}$. There is an accumulating international literature on public health nutrition effectiveness ${ }^{22,23,28}$. The features of successful interventions highlighted from these reviews are summarised in Table 2. 
Table 1 Description of the workforce development framework with reference to intelligence sources and current analysis for Australia

\begin{tabular}{|c|c|c|c|}
\hline Stage & Rationale & $\begin{array}{l}\text { Intelligence source } \\
\text { examples }\end{array}$ & Australian analysis \\
\hline $\begin{array}{l}\text { Problems and } \\
\text { priorities }\end{array}$ & $\begin{array}{l}\text { A focus on public health (nutrition) } \\
\text { problems and priorities is required to } \\
\text { ensure workforce development } \\
\text { investments achieve the optimal } \\
\text { return and reflect population } \\
\text { health goals }\end{array}$ & $\begin{array}{l}\text { Monitoring and surveillance } \\
\text { Research (e.g. burden } \\
\text { of disease studies) } \\
\text { Community consultation } \\
\text { Health sector priority } \\
\text { rationales } \\
\text { Expert opinion }\end{array}$ & $\begin{array}{l}\text { In Australia the national strategic plan } \\
\text { for public health nutrition }{ }^{20} \text { has iden- } \\
\text { tified priority issues for public health } \\
\text { nutrition action and provides a basis } \\
\text { for focusing workforce efforts }\end{array}$ \\
\hline $\begin{array}{l}\text { Solutions and } \\
\text { best buys }\end{array}$ & $\begin{array}{l}\text { Intervention research (formal efforts } \\
\text { to design, evaluate and improve } \\
\text { the effectiveness of public health } \\
\text { nutrition interventions) can inform } \\
\text { investment decisions. Knowledge } \\
\text { of what works, why and where are } \\
\text { important sources of intelligence for } \\
\text { workforce development as it can } \\
\text { inform considerations about the } \\
\text { work required }\end{array}$ & $\begin{array}{l}\text { Intervention research } \\
\text { Determinant analysis } \\
\text { Reflective practice } \\
\text { Experiential learning }\end{array}$ & $\begin{array}{l}\text { There is a limited intervention } \\
\text { research literature, including } \\
\text { effectiveness reviews conducted in } \\
\text { Australia }^{21} \text { and internationally } 22,23 \\
\text { Models for determinant analysis } \\
\text { developed to inform portfolio } \\
\text { development in public health }\end{array}$ \\
\hline Work needed & $\begin{array}{l}\text { The work needed to implement } \\
\text { solutions to address identified } \\
\text { problems/priorities is commonly } \\
\text { referred to as core functions. } \\
\text { Core functions provide a description } \\
\text { of the work required. This in } \\
\text { turn can be used to compare with } \\
\text { current work practices and workforce } \\
\text { characteristics to identify } \\
\text { workforce deficits and strengths }\end{array}$ & $\begin{array}{l}\text { Core functions }{ }^{17,25} \\
\text { Current practice review } \\
\text { Employer expectations }\end{array}$ & $\begin{array}{l}\text { Core functions for public health have } \\
\text { been developed }{ }^{17} \text { but they are not } \\
\text { specific to public health nutrition. } \\
\text { Currently there is limited intelligence } \\
\text { about workforce practices or } \\
\text { employer's expectations }\end{array}$ \\
\hline Capacity to do work & $\begin{array}{l}\text { The capacity of the workforce to do } \\
\text { the work identified depends on a } \\
\text { combination of workforce size, } \\
\text { composition, competency mix and } \\
\text { support (influenced by and including } \\
\text { resource allocation, leadership, } \\
\text { organisational support and access } \\
\text { to intelligence) }\end{array}$ & $\begin{array}{l}\text { Workforce } \\
\text { enumeration/profiling } \\
\text { Continuing professional } \\
\text { development needs } \\
\text { assessment } \\
\text { Organisational and policy } \\
\text { structure review/analysis }\end{array}$ & $\begin{array}{l}\text { Intelligence limited to studies targeting } \\
\text { the dietetic workforce } 26-30 \text { and } \\
\text { unpublished studies of the } \\
\text { community nutrition workforce }^{31}\end{array}$ \\
\hline $\begin{array}{l}\text { Workforce development } \\
\text { needed }\end{array}$ & $\begin{array}{l}\text { Information about workforce develop- } \\
\text { ment strategies and evaluation, } \\
\text { existing workforce preparation and } \\
\text { barriers to workforce development } \\
\text { are important in developing } \\
\text { strategic approaches to } \\
\text { workforce development }\end{array}$ & $\begin{array}{l}\text { Competencies literature } \\
\text { Competency development } \\
\text { research } \\
\text { Workforce development } \\
\text { intervention research } \\
\text { Practitioner consultation }\end{array}$ & $\begin{array}{l}\text { Competency literature limited to } \\
\text { entry-level dietetics }{ }^{32-34} \text {. No known } \\
\text { workforce development literature }\end{array}$ \\
\hline
\end{tabular}

Identifying effective strategies and interventions can inform workforce development planning because it helps isolate the various types of work required by the workforce.

\section{Work needed}

Various attempts have been made to identify the work needed of the public health workforce as reflected by core functions or essential services ${ }^{17,25,43}$. Comparison of this core functions work between countries indicates considerable similarity in statements about the work needed by the public health workforce, such as monitoring and surveillance, intervention management (needs assessment, planning, implementation, evaluation), policy and legislative measures and public health service delivery. Given that public health nutrition is a field of public health work, these public health core functions have currency when considering public health nutrition functions and the work these imply. One of the challenges in public health nutrition workforce development is similarly to identify the specific functions or work required of the public health nutrition workforce to inform workforce development initiatives. To identify workforce development needs, one has to know what the functions of the workforce should be and develop the workforce accordingly.

\section{Capacity to do work}

Consideration of the workforce's capacity to do the required work should include not only analysis of the composition of the workforce (who), enumeration (how many), existing practices and competencies but also the organisational environment of the workplace. This follows a systems approach to workforce development proposed for the public health workforce that identifies the worker, 
Table 2 Main features of past successful public health and nutrition campaigns

\begin{tabular}{ll}
\hline Feature of campaign & Reference \\
\hline Investment in understanding the determinants of & 21,22 \\
$\quad$ a nutrition problem & \\
Community participation is essential & 41 \\
Adequate duration, size and sophistication of & 23,41 \\
interventions & 38,41 \\
A slow and staged approach & $21,23,41,42$ \\
Investment in thorough intervention planning & 22,38 \\
Legislative action & $22,23,38$ \\
Education & 22,23 \\
Environmental change & 21,22 \\
Social interaction and support to facilitate & 21,38 \\
change & $21,24,38$ \\
Advocacy & $23,41,42$ \\
Intersectoral responsibility and action & \\
Strategies based on theories of behaviour & 22 \\
change & 22 \\
Economic incentives to encourage healthy eating & 22 \\
Attention given to creating the necessary & \\
$\quad$ conditions for successful implementation of a & \\
programme & 21 \\
A bias for action & 24 \\
Adequate infrastructure to support action & 24 \\
Emphasis on evaluation & \\
\hline
\end{tabular}

the nature of the work and the work organisation as components of the system ${ }^{5}$. The workforce's access to intelligence to inform effective practice and the necessary physical infrastructure such as equipment are also likely to impact on the workforce's capacity to address public health nutrition issues effectively. The importance of considering all of these determinants of workforce capacity has recently been illustrated in Australia, where an assessment of the capacity of the public health nutrition workforce in the state of Victoria has shown a specialist workforce constrained by service and organisational orientations that have limited population-based and preventive service delivery ${ }^{44}$.

\section{Workforce composition}

It is quoted amongst applied nutrition professionals that 'nutrition is not a discipline to be studied: it is a problem to be solved'. If this is true, then - by definition - solving nutrition problems requires multidisciplinary co-operation $^{13}$. In the broadest sense, the public health nutrition workforce could be considered as all those who make a contribution to organised efforts to protect and promote health through better nutrition. However, this broad view is problematic for workforce development as it is difficult to identify target groups for development and limited resources for workforce development require a prioritisation of investment.

In order to address this difficulty of defining the workforce in related areas of public health, variations on a multi-tiered workforce model have been proposed in Australia for the public health ${ }^{45}$, health promotion ${ }^{1}$ and public health nutrition workforces ${ }^{46}$. Each of these multitier models includes a distinction between specialists with specific competencies, roles and mandates for work in the area, generalists with broad competency bases who may work in the field of nutrition on a part-time or ad hoc basis and other health workers who make variable contributions to the work needed. Delineating the various workforce tiers is important in systematic workforce development because the different contributing work groups will have different development needs. Intelligence about the different workforce development needs can inform prioritisation of strategy investments. In Australia, a recent application of this approach to public health nutrition workforce development has identified dietitians as an initial priority workforce group for development. This is because of the considerable existing competencies relevant to public health nutrition, greater access to opportunities to apply new competencies in the workplace and the leadership and nutrition facilitation role this group plays in the local health system ${ }^{47}$.

\section{Workforce enumeration and profile}

The size of the workforce relevant to the scale of the work needed has obvious implications for the capacity of the workforce to implement solutions to identified problems. Profiling the public health nutrition workforce is essential in order to be able to assess the capacity of the public health nutrition workforce to perform nominated core functions ${ }^{48}$.

This involves more than just counting the workforce, and is currently difficult to achieve. Public health workforce development scholarship in the USA ${ }^{49,50}$ has outlined some of the limitations that hamper the ability to enumerate the public health workforce, which are relevant to public health nutrition workforce studies (Table 3).

There have been few studies published attempting to profile the demographic, educational or practice characteristics of national public health nutrition workforces. These studies ${ }^{48,51,52}$ have been discipline-specific (or focus on the specialist tier) rather than multidisciplinary in focus. Further efforts to enumerate and profile the public health nutrition workforce are required to support workforce development planning.

\section{Current workforce practices}

Analysis of the work being undertaken by the workforce is arguably as important as analysis of workforce size. In the context of public health nutrition, work that focuses on implementing public health nutrition functions to address identified problems influences workforce effectiveness. This analysis might include reviews of workforce strategy utilisation and intervention activity as well as specific workforce practice quality assurance studies. It is critical to be able to identify determinants of workforce activity and practice such as the effects of workforce preparation, competency gaps, organisational restrictions on practice and access to intelligence to inform service delivery. At present, there are few studies of this nature in the literature. 
Table 3 Public health nutrition workforce study methodological issues and limitations

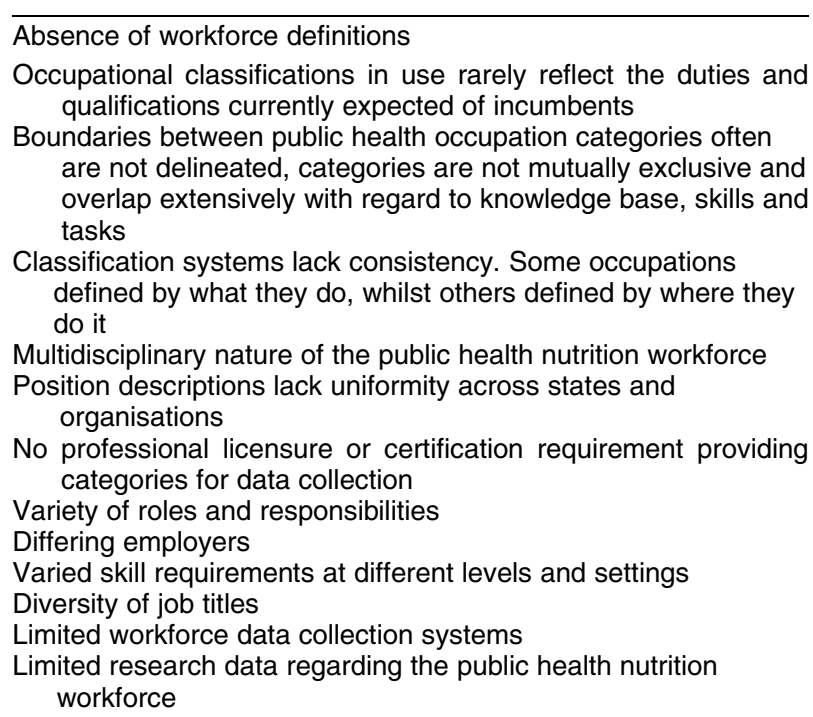

Source: Adapted from references 45, 49 and 50.

\section{Workforce preparedness and existing competencies}

Training and education received prior to workforce entry contribute significantly to workforce preparedness to do the necessary work. There have been few attempts critically to assess how efficient the existing university and profession-based education system is in preparing the workforce for public health nutrition work. In Australia, an unpublished state-wide survey of the dietetics profession in $1998^{53}$ reported that only one-third of graduates who graduated in the past 10 years felt confident to practice in community nutrition on graduation and only $15 \%$ for public health practice. This suggests either inadequacy in dietetic education and/or the post-basic nature of competencies required for practice in this field.

\section{Organisational commitment/mandates for action}

The capacity of the workforce to address identified problems can be determined by their organisational environment. Without a mandate for practising in a population-based and preventive mode, workers may be constrained by a lack of management support and the associated resource allocations necessary to undertake the required work. Assessment of the organisational support of the workforce and the employment context is therefore a critical component of workforce development intelligence gathering and planning.

\section{Access to intelligence to support effective intervention management}

Workforce practices, resource allocation decisions and subsequent effectiveness can be determined by access to information that best informs strategic approaches to problem resolution. Intelligence from intervention research (which answers questions such as which interventions work, when, how and on who?) and research that assists determinant analysis are examples.

\section{Physical infrastructure}

The workforce's access to physical infrastructure such as vehicles to reach communities, and computers and information systems to assist research and communication, has obvious impacts on workforce capacity, resource allocation decisions and priorities. It therefore should be considered when investigating the public health nutrition workforce capacity and the most effective workforce development strategies.

\section{Workforce development needed}

Workforce development has been defined as strategies that influence the environment affecting the training, work practice and careers of practitioners/workers ${ }^{19}$. Systematic approaches to workforce development in public health have previously highlighted the relationships between the work, the worker and the work setting ${ }^{5}$. It is likely that effective workforce development requires multiple strategies.

Workforce development strategies should focus on addressing factors that limit workforce capacity to solve identified problems. Using the framework presented in this paper, workforce development strategy planning draws on the intelligence obtained and considered in the earlier stages of the system. This may by complemented by intelligence from early workforce development interventions research. This intelligence source, however, is currently limited, particularly in the specific field of public health nutrition. This supports a need for further investigation of workforce development strategies' effectiveness, particularly given the potential limitations of focusing on training as a workforce strategy in isolation of other capacity issues mentioned in this discussion so far.

Workforce development intervention research is also important given the additional investment of resources required for many of the workforce development strategies such as workforce growth (new positions), service organisation restructuring, extra training and physical infrastructure investments. Fund allocation to support workforce development needs to be informed by intelligence and these investments need to be evaluated for effectiveness.

Systematic models for workforce development have been proposed for the public health workforce $e^{3,5,49}$ and include elements that include incentives for further development (e.g. career structures that recognise and remunerate specialisation) and assurance of financial support (e.g. long-term funding and job security). A systems approach to public health workforce development suggests that advancements in workforce competence may require major organisational development and redesign efforts in the public health sector. 
Organisations will need to become learning systems. It has been argued that creating the organisational capacity to enable knowledge creation and use may be the greatest determinant of how public health agencies perform in the twenty-first century. The skills and knowledge necessary to create this capacity will be central to the new set of essential competencies required for leadership in public health ${ }^{5}$. These points are relevant to public health nutrition workforce development.

\section{Competencies and continuing professional development} Competencies provide the architecture for workforce development because they function to inform curriculum development, continuing professional development, recruitment and performance review. Competencyrelated scholarship relative to public health nutrition is evident world-wide $6,7,11-14,31,54,55$. The similarities in the competency needs identified in these studies suggest a developing international consensus on a core set of competencies for public health nutrition.

Studies that investigate or assess the continuing professional development needs of the various tiers of the workforce can also be used to provide intelligence on workforce development needs. These needs reflect not only the limitations of previous workforce preparation but also identify development needs of the workforce. Further research is required to investigate the most effective strategies for developing the specialist competencies required for effective public health practice.

\section{Conclusions}

This framework illustrates the intelligence needs for systematic and problem-based workforce development. It can be used to identify existing gaps in the intelligence required to inform workforce development and focus workforce research efforts. The obvious conundrum with identifying workforce development intelligence gaps and needs is that it usually identifies a need for more work. In scenarios with under-developed workforces, finding enough staff with the necessary competencies to conduct and sustain the necessary intelligence base will require a mix of work prioritisation, service reorientation and greater collaboration between practitioners, academics and the communities they serve.

\section{References}

1 National Health and Medical Research Council. Promoting the Health of Australians: A Review of Infrastructure Support for National Health Advancement: Final Report. Canberra: Australian Government Publishing Service, 1996.

2 Landman J. Training in public health nutrition: symposium at the 17 th International Congress of Nutrition, Vienna. Public Health Nutrition 2001; 4: 1301-2.
3 Lichtveld M, Cioffi J, Baker E Jr, Bailey SB, Gebbie K, Henderson JV, et al. Partnership for front-line success: a call for a national action agenda on workforce development. Journal of Public Health Management and Practice 2001; 7 : $1-7$.

4 Centers for Disease Control and Prevention/Agency for Toxic Substances and Disease Registry. Strategic Plan for Public Health Workforce Development. Toward a Life-long Learning System for Public Health Practitioners. Washington, DC: US Department of Health and Human Services, 2001.

5 Kennedy V, Moore F. A systems approach to public health workforce development. Journal of Public Health Management and Practice 2001; 7: 17-22.

6 Dodds J, Polhamus B. Self-perceived competence in advanced public health nutritionists in the United States. Journal of the American Dietetic Association 1999; 99: 808-12.

7 Hess A, Haughton B. Continuing education needs for public health nutritionists. Journal of the American Dietetic Association 1996; 96: 716-8.

8 Landman J, Buttriss J, Margetts B. Curriculum design for professional development in public health nutrition in Britain. Public Health Nutrition 1998; 1: 69-74.

9 Yngve A, Sjostrom M, Warm D, Margetts B, Rodrigo CP, Nissinen A. Effective promotion of healthy nutrition and physical activity in Europe requires skilled and competent people; European Master's Programme in Public Health Nutrition. Public Health Nutrition 1999; 2: 449-52.

10 New South Wales (NSW) Health. A Framework for Building Capacity to Improve Health. Sydney: NSW Health, 2001.

11 Olmstead-Schafer M, Story M, Haughton B. Future training needs in public health nutrition: results of a national delphi survey. Journal of the American Dietetic Association 1996; 96: $282-3$.

12 Corby L. Assessment of community development and leadership skills required by Caribbean nutritionists and dietitians: research and international collaboration in action. Journal of Nutrition Education 1997; 29: 250-7.

13 Rogers B, Schlossman N. 'Public nutrition': the need for cross-disciplinary breadth in the education of applied nutrition professionals. Food and Nutrition Bulletin 1997; 18: $120-33$.

14 Pelletier D. Advanced training in food and nutrition: disciplinary, interdisciplinary, and problem orientated approaches. Food and Nutrition Bulletin 1997; 18: $134-45$.

15 Ruderman M, Grason H. Public health workforce development: keeping population health goals in mind. Journal of Public Health Management and Practice 2002; 8: $84-6$.

16 National Public Health Partnership (NPHP). National Delphi Study on Public Health Functions in Australia. Melbourne: NPHP, 2000.

17 National Public Health Partnership (NPHP). Public Health Practice in Australia Today - Core Functions. Melbourne: NPHP, 2001.

18 Hutchins C. Health Promotion Workforce Development: A Snapshot of Practice in Australia. Draft Report. Melbourne: Health Promotion Association of Australia, 2002.

19 Riddout L, Gadiel D, Cook K, Wise M. Planning Framework for the Public Health Workforce. Discussion Paper. Melbourne: National Public Health Partnership, 2002.

20 Strategic Intergovernmental Nutrition Alliance. Eat Well Australia: An Agenda for Action for Public Health Nutrition 2000-2010. Canberra: Department of Health and Aged Care, 2001.

21 Victorian Department of Human Services. Health Promotion Strategies for Community Health Services: An Evidencebased Planning Framework for Nutrition, Physical Activity 
and Healthy Weight. Melbourne: Victorian Department of Human Services, 1998.

22 International Union of Health Promotion and Education (IUHPE). The Evidence of Health Promotion Effectiveness: A Report to the European Commission by the IUHPE. Brussels: IUHPE, 2000.

23 Health Education Authority (HEA). Health Promotion Interventions to Promote Healthy Eating in the General Population - A Review. London: HEA, 1997.

24 National Public Health Partnership (NPHP). A Planning Framework for Public Health Practice - A System Perspective. Melbourne: NPHP, 1999.

25 US Department of Health and Human Services (DHHS). The Essential Public Health Services Work Group of the Core Public Health Functions Steering Committee. Washington, DC: DHHS, 1995.

26 Scott J, Binns C. A profile of dietetics in Australia: Part 1 Demography and educational characteristics. Journal of Food and Nutrition 1988; 45: 77-9.

27 Scott J, Binns C. A profile of dietetics in Australia: Part 2 Employment characteristics. Australian Journal of Nutrition and Dietetics 1989; 46: 14-7.

28 Hughes R. An omnibus survey of the Australian rural health dietetic workforce. Australian Journal of Nutrition and Dietetics 1998; 55: 163-9.

29 Williams P. Trends in the New South Wales dietetic workforce 1984-1991. Australian Journal of Nutrition and Dietetics 1993; 50: 116-9.

30 Meyer R, Gilroy R, Williams P. Dietitians in NSW: workforce trends 1984-2000. Australian Health Review 2002; 25: $122-30$.

31 Steele J. Towards a public bealth nutrition buman resource infrastructure in Queensland. Master of Public Health thesis, University of Queensland, Brisbane, 1995.

32 Phillips S, Ash S, Tapsell L. Dietitians' views on the current competency standards for entry level dietitians. Australian Journal of Nutrition and Dietetics 2000; 57: 190-7.

33 Phillips S, Ash S, Tapsell L. Relevance of the competency standards to entry level dietetic practice. Australian Journal of Nutrition and Dietetics 2000; 57: 198-207.

34 Ash S, Phillips S. What is dietetic competence? Competency standards, competence and competency explained. Australian Journal of Nutrition and Dietetics 2000; 57: $147-51$.

35 Mathers C, Vos T, Stevenson C. The Burden of Disease and Injury in Australia: Summary Report. Canberra: Australian Institute of Health and Welfare, 1999.

36 Public Health Division. Burden of Disease 1996: Local Government Areas and Regions in Victoria. Melbourne: Victorian Department of Human Services, 2000.

37 Crowley S, Antioch K, Carter R, Waters A, Conway L, Mathers C. The Cost of Diet-related Disease in Australia. Canberra: Australian Institute of Health and Welfare, 1992.

38 World Health Organization (WHO). Obesity: Preventing and Managing the Global Epidemic. Geneva: WHO, 1997.

39 World Cancer Research Fund (WCRF)/American Institute for Cancer Research (AICR). Food, Nutrition and the Prevention of Cancer: A Global Perspective. Washington, DC: WCRF/AICR, 1997.
40 Miller M, Stafford H. Framework trial to develop an intervention portfolio to promote fruit and vegetables summary report to the National Public Health Partnership, Melbourne, 2000 [unpublished].

41 Nutbeam D. Health promotion effectiveness - the questions to be answered. In: The Evidence of Health Promotion Effectiveness: A Report to the European Commission by the IUHPE. Brussels: International Union of Health Promotion and Education (IUHPE), 2000; 1-11.

42 Gok G. Why are so many health promotion programs ineffective? Health Promotion Journal of Australia 1993; 3: $12-7$.

43 Sapirie S. Essential Public Health Functions. Geneva: World Health Organization, 1999.

44 Hughes R, Woods J. A Needs Assessment for Public Health Nutrition Workforce Development in Victoria. Melbourne: Monash University-Griffith University Partnership, 2002.

45 Public Health Association of Australia. Workforce Issues for Public Health. The Report of the Public Health Workforce Study. Canberra: Public Health Association of Australia, 1990.

46 Campbell K, Steele J, Woods J, Hughes R. Developing a Public Health Nutrition Workforce in Australia: Workforce Issues. Melbourne: National Specialty Program in Public Health and Community Nutrition, 1997.

47 Hughes R, Woods J. A Strategic Plan for Public Health Nutrition Workforce Development in Victoria. Melbourne: Monash University-Griffith University Partnership, 2002.

48 Haughton B, Story M, Keir B. Profile of public health nutrition personnel: challenges for population/systemfocused roles and state-level monitoring. Journal of the American Dietetic Association 1998; 98: 664-70.

49 US Department of Health and Human Services (DHHS). The Public Health Workforce: An Agenda for the 21st Century. A Report of the Public Health Functions Project. Washington, DC: DHHS, 2001.

50 Gebbie K, Merrill J. Enumeration of the public health workforce: developing a system. Journal of Public Health Management and Practice 2001; 7: 8-16.

51 Adamson A, Cowburn G. Community nutrition and dietetics: a survey of nutrition group members in 1995. Journal of Human Nutrition and Dietetics 1996; 9: 339-48.

52 Gatchell S, Woolcott D. A demographic profile of Canadian public health nutritionists. Journal of the Canadian Dietetic Association 1992; 53: 30-4.

53 Anthony H, Cooper C. Summary report on public health and community nutrition activities carried out by Victorian members of the Dietitians Association of Australia, Melbourne, 1998 [unpublished].

54 Story M, Neumark-Stzainer D, Ireland M, Evans T. Adolescent health and nutrition: a survey of perceived knowledge and skill competencies and training interests among dietitians working with youth. Journal of the American Dietetic Association 2000; 100: 362-4.

55 Sims L, Kohli M. Predictors of effectiveness among public health nutritionists. American Journal of Public Health 1983; 73: $1376-80$. 